Revista de la red interuniversitaria de estudios sobre las literaturas rioplatenses contemporáneas en Francia

$18 \mid 2018$

El río y la ciudad

\title{
Vistas y luces en el Río de la Plata durante el Sitio de Montevideo
}

\section{Adriana Amante}

\section{OpenEdition}

\section{Journals}

Edición electrónica

URL: http://journals.openedition.org/lirico/5906

DOI: 10.4000/lirico.5906

ISSN: 2262-8339

Editor

Réseau interuniversitaire d'étude des littératures contemporaines du Río de la Plata

\section{Referencia electrónica}

Adriana Amante, «Vistas y luces en el Río de la Plata durante el Sitio de Montevideo », Cuadernos LIRICO [En línea], 18 | 2018, Puesto en línea el 15 noviembre 2018, consultado el 21 abril 2019. URL http://journals.openedition.org/lirico/5906 ; DOI : 10.4000/lirico.5906

Este documento fue generado automáticamente el 21 abril 2019.

\section{cc) $(1) \odot$}

Cuadernos LIRICO está distribuido bajo una Licencia Creative Commons Atribución-NoComercialSinDerivar 4.0 Internacional. 


\title{
Vistas y luces en el Río de la Plata durante el Sitio de Montevideo
}

\author{
Adriana Amante
}

\section{I}

1 La Montevideo sitiada por Manuel Oribe entre febrero de 1843 y octubre de 1851 se ofreció a múltiples grafías: literarias, plásticas, topográficas. La ciudad fue representada en textos literarios, en vistas o en planos del terreno en el que se desarrollaron el asedio y la defensa de la plaza y en el que ciertos puntos de referencia (el Cerro, la Matriz, el fuerte, la muralla, el Cerrito) se convirtieron en ejes determinantes para las configuraciones técnicas, estéticas y simbólicas que circularon y disputaron en la política rioplatense de bandos donde se enfrentaban los orientales, divididos entre los blancos de Manuel Oribe y los colorados de Fructuoso Rivera, y sobre la que amplió su dominio el argentino Juan Manuel de Rosas.

2 Viajero al fin, aun si con la carga agobiante del destierro, Domingo F. Sarmiento ve por primera vez Montevideo en diciembre de 1845: como los pintores que deambulaban entre el Río de la Plata y el Janeiro diseñó vistas y panoramas. Y más precisamente, tal vez sin quererlo o incluso sin saberlo, con los ojos de Adolphe D'Hastrel de Rivedoux. Ojos que conocían de pintura pero también de técnicas militares; conjunción de saberes que dirigió de modo experto el trazado de sus vistas. 


\section{Veiase por fin el rio cubierto de naves ancladas en distintos puntos, como el gaucho amarra su caballo en donde le sorprende la noche, o halla pasto.abundante en la pampa solitaria, i a lo le- jos un vistoso grupo de torres i miradores, seña- laba, aparentemente a la sombra del cerro que le dí́ nombre, la presencia de Montevideo. La ciudad en tanto se presentaba a nuestro escruti- nio con una coqueteria que pocas pueden osten- tar. Rueda el buque en torno de ella buseando}

Facsímil $1^{1}$

3 Sarmiento diseña una vista de Montevideo que reincide en la analogía entre la pampa y el mar, que en este caso es río, aventurada didácticamente por los viajeros ingleses a los que tanto él como Alberdi o Echeverría leyeron. Pero acá el sentido se invierte y, con el Facundo ya en la memoria de su lector, ahora el curso de agua es el que puede parecerse a la pampa y la pampa convertirse en el epítome conceptual de la región del Plata, aunque las cuchillas de Montevideo puedan desmentir la figura.

4 Vista de Montevideo desde la rada podría titularse ese párrafo de la carta desde la ciudad sitiada que Sarmiento dirige a su íntimo amigo Vicente F. López y que incluirá en la primera entrega de sus Viajes por Europa, África y América, editada en 1849. La rada -zona en la que los barcos pueden anclar sin peligros de encallamiento- es un umbral: punto de llegada de la travesía y lugar desde el cual se realiza el primer avistamiento de la ciudad. Desde la rada, la vista se lanza a través de la malla que tejen las sogas de los mástiles de las naves de velas latinas que suelen agitar las escenas acuáticas del escritor sanjuanino. El primer contacto con una ciudad, el arribo, está marcado por una distancia espacial y una distancia temporal: se la ve a unas leguas de distancia y el desembarco nunca es inmediato. Si es que se desembarca. Porque a veces las ciudades son solo puertos de paso, escalas técnicas necesarias para viajeros en tránsito o para científicos en exploración, o zonas de posicionamiento estratégico para marinos en asedio.

5 Vista de Montevideo desde la rada; entonces, la de Sarmiento, para parafrasear esa Vue géneral, prise de la Rade (1842) que forma parte del Álbum de la Plata que D’Hastrel edita probablemente en 1845, ya de regreso en Francia ${ }^{2}$. 


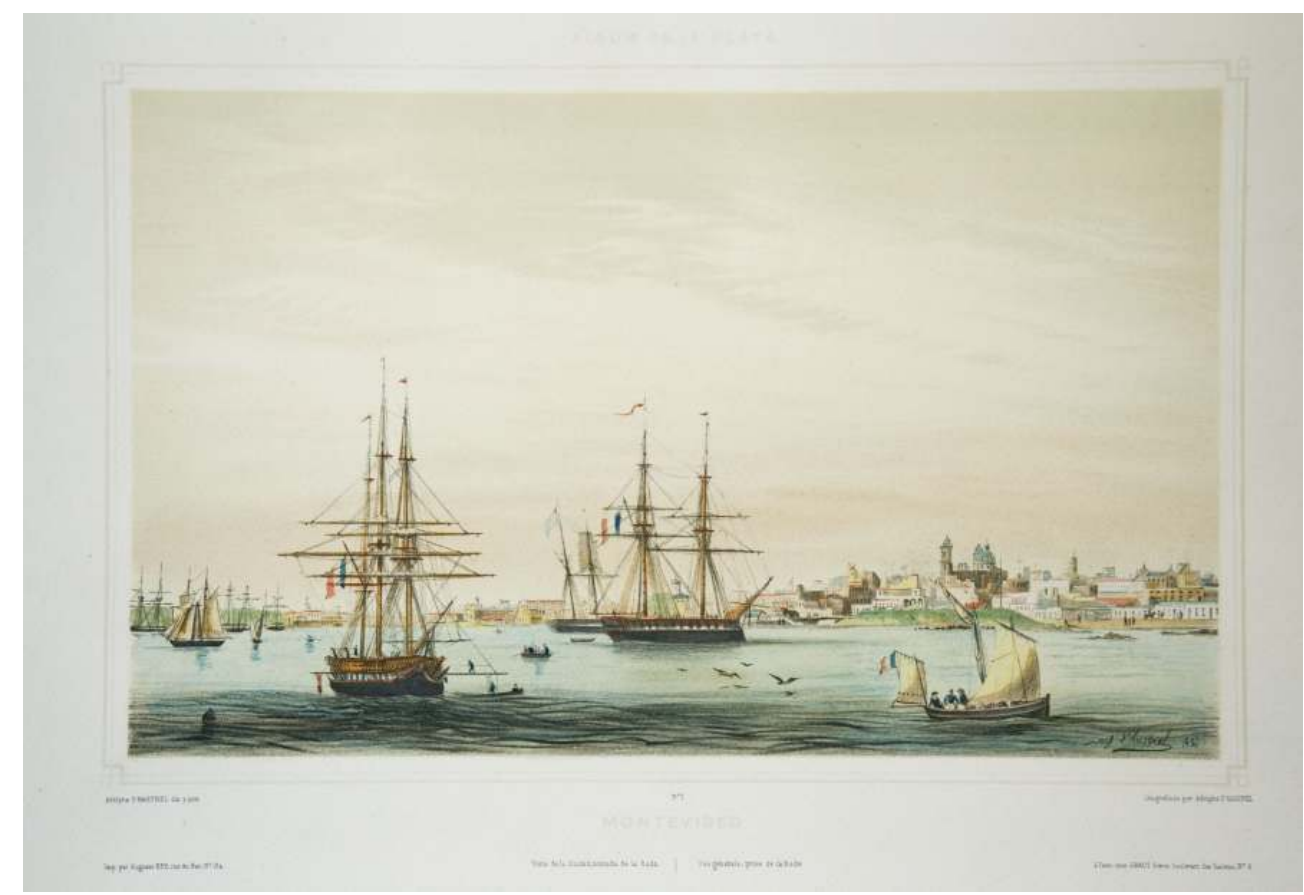

Figura 1: Adolphe D’Hastrel, Vue géneral, prise de la Rade ${ }^{3}$

6 Allí se ven las sogas y los mástiles de los barcos, los marinos diligentes ayudando en el traspaso a las chalupas que llevarán a tierra a los que arriban, las aves que revolotean con la esperanza cierta de algún alimento y las banderas tricolor del país de origen. Una vista desde la rada, con sus tres franjas y tres planos habituales para el género: la orla de agua en la que se instala el punto de vista; la fina lonja horizontal de tierra, escandida por verticales de torres y miradores; y el cielo generoso contra el que se recortan ${ }^{4}$. Esta vista de la ciudad también es coqueta (acaso porque la ciudad misma en efecto lo es).

tar. Rueda el buque en torno de ella buscando desde el lado del Océano el ancladero que guardan la ciudad i el Cerro, i en aquellas viradas de bordo que la barca describe como los jiros del ave

acuática que se dispone a posarse sobre las aguas, van presentándose las calles que cruzan la poblacion, i caen de punta bajo el ojo, primero de norte a sur, despues de poniente a naciente, $i$ to. davía de norte a sur, con su variedad infinita de grupos i de trajes, de carruajes i de jinetes, interrumpiendo la perspectiva las ondulaciones del terreno que lo asemejan a espuma del rio petrificada. Dan realee a estavista el material de- 
7 Sarmiento percibe con los modelos ópticos que ha interiorizado. Ha aprendido a guiar el ojo para ver y a entender sistemas de representación para diseñar. Por eso, después de desplegar una vista inicial en panorama, puede atreverse a esta vista de vuelo de pájaro que encuentra desde un punto, aunque sea una mínima elevación, la posibilidad de acercarse y abarcar, más en profundidad que en la silueta o el perfil urbano que se recortaba sobre la costa, las líneas sinuosas del trazado interno de las calles en las que se mueven anónimos habitantes que se trasladan a pie, en carruajes o a caballo. Aparecen así las calles como surcos que van de norte a sur, para cruzarse con los que se extienden de oeste a este (como ha aprendido leyendo libros de geografía o de viajeros, Sarmiento ordena la composición de acuerdo con los puntos cardinales). Casi como en una xilografía, en la que se horada la superficie de madera con un buril y que encuentra en la Vista a vuelo de pájaro de Venecia (1500) de Jacopo de' Barbari su antecedente más monumental. En una vista como esta -propone Giuliana Bruno- se produce el encuentro entre el paisaje y el mapa y se abre la posibilidad a un espacio narrativo. ${ }^{6}$

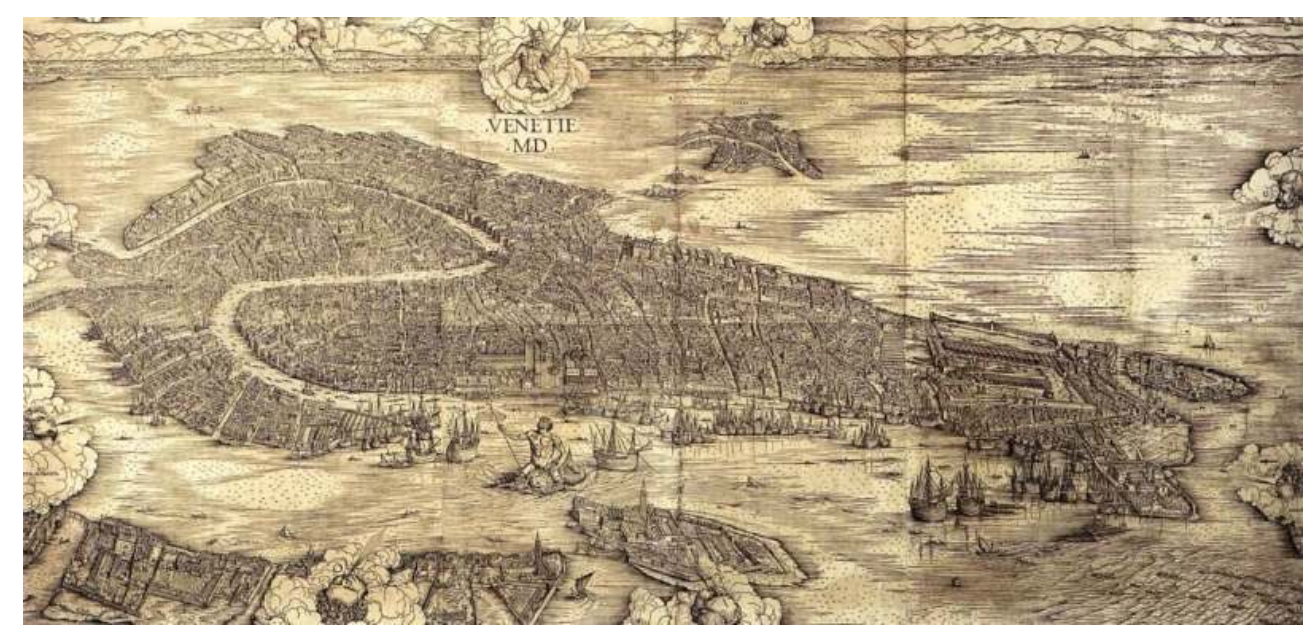

Figura 2: Jacopo de' Barbari, Veduta di Venezia a volo d'uccello (Xilografía, 1500)

8 Sarmiento intuye la textura de una ciudad por la que todavía no ha transitado, pero que le anticipa por la vista la vida de sus habitantes y la materialidad de la cal de esas casas de "arquitectura morisca" que tienen "sus techos planos", característica que le hace compartir con esa Buenos Aires que todavía tampoco conoce, pero a la que no pudo ni podrá siquiera observar desde la rada.

9 Se trata de otra percepción orientalista de Sarmiento, que ya ha desplegado gran parte de su artillería analógica para confundir la barbarie pampeana con la de los pueblos musulmanes en una sola condena al atraso. En la apreciación de Montevideo, de todos modos, antes que para enjuiciar, Sarmiento señala el exotismo en un gesto de valoración de la estética colonial española que aliviana con la azotea la percepción visual, en contraposición con la arquitectura del Pacífico, a la que no se cansa de criticar por tener también antepechos y balcones del todo inapropiados para zonas sísmicas tanto como por sus adecuados pero pesados mojinetes. ${ }^{7}$

Enseguida analizará que en Montevideo, 
nes del a derno-gusto-ingles-; la con verjas de fierro, a mas de dar transparencia i lijereza al remate, hace el efecto de jardines, de cuyo seno se elevara el cuadrangular, esvelto i blanco mirador, que a esta hora de la tarde está engalanado, vivificado, con grupos de jente que esparcen su vista i aspiran la brisa pura del rio.

Facsímil $3^{8}$

La vista se invierte: ya no son las terrazas y miradores los que se observan desde el río, cuando se llega, sino el río el que se ve desde las azoteas. Desde ahí, los mástiles de los barcos con las velas plegadas que se mecen en la rada, pero también el peligro o la amenaza del enemigo cercano, que para la historia del Río de la Plata alterna y combina los personajes de una margen o de la otra, confundiendo las políticas, las naciones y los sentidos.

La imagen de Sarmiento puede vincularse a otro cuadro de D'Hastrel, Las terrasses avec vue sur la grand-rade et le phare du Cerro (Vista de las azoteas y de la rada), que compone en primer plano el dédalo de terrazas, balcones y miradores que se superponen como cubos en parte color blanco y en parte color siena, para ubicar la adelgazada línea del agua en el segundo plano y extender atrás y arriba el cielo nebuloso sobre el que se levanta el "cerro que le dio su nombre" a la ciudad:

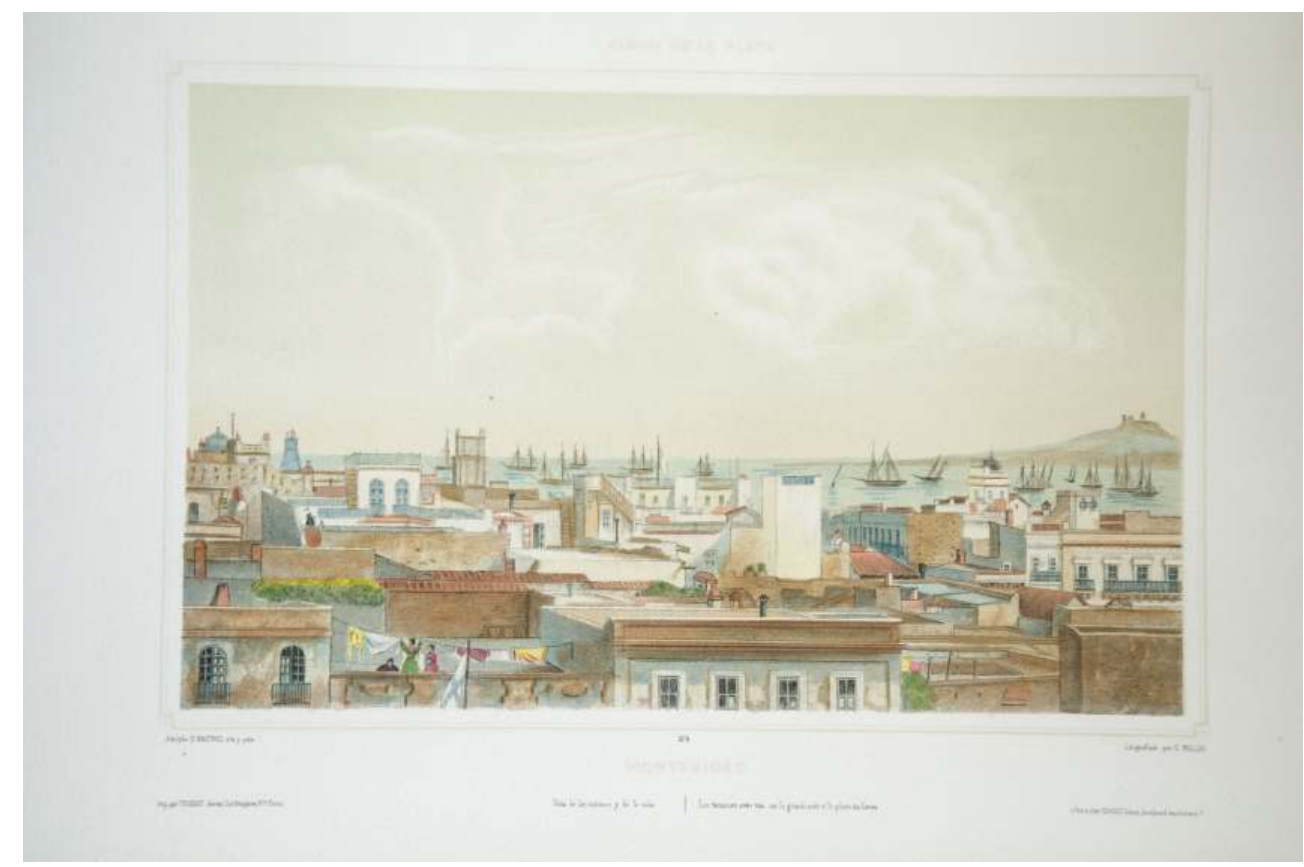

Figura 3: Adolphe D'Hastrel, Las terrasses avec vue sur la grand-rade et le phare du Cerro (Vista de las azoteas y de la rada) 
II

13 Volvamos al río, y al texto: Sarmiento entra morosamente al puerto de Montevideo porque la escritura necesita solazarse, no solo en el espacio natural o en la captación del perfil urbano, sino también en sus propias rumiaciones. Así, el río púrpura (efecto óptico de sugestión, que lee los infusorios microscópicos del lecho en clave política contra el "tirano" que impone el rojo punzó a fuerza de degüello, según el comentario sarcástico del capitán del barco) lo llevará a Sarmiento a una evocación histórica que recupera la historia "sangrienta" y la "existencia guerrera" del Río de la Plata, en las que Guillermo Brown se instala -metonimia por Rosas- como "el viejo tirano de estas aguas" desde 1812, y al que el bravo Giuseppe Garibaldi, aunque a la cabeza de "inauditas y osadas empresas", no logra doblegar (p. 34).

Sangrienta en efecto es su historia, gloriasa a la par que estéril. Naumaquia permanente que a una u otra ribera tiene cual anfiteatros dos ciudades espectadores, que han tenido desde mucho tiempo la costumbre de lanzar de sus pertos naves cargadas de gladiadores para teñir sus aguas con inutiles combates. Montevideo i Buenos Aires conservan su arquitectura morisca, sus techos planos, i sus miradores que dominan hasta mui lejos la superficie de las aguras. Ia brisa de-

FACSÍMIL 4

[...]

Si la tempestad turba el ancho rio, si las naves batidas por la borrasca no pueden ganar el difícil puerto, si la bandera o el cañon piden a la vecina costa socorro, si la escuadra enemiga asoma sus siniestras velas, Montevideo i Buenos Aires acuden alternativamente a sus atalayas $i$ azoteas a hartarse de emociones, a endurecer sus nérvios con el espectaculo del peligro, la saña de los elementos, o la violencia de los hombres. Fn 1826, , 
iespliega el lienzo de fondo y dispone los elementos para el espectáculo experto regisseur como se hizo estando todavía en San Juan, merced a que Antonino Aberastain lo nombró primer decorador del teatro y salón de baile de la joven Sociedad Dramático-Filarmónica y gracias a que, desde sus tempranos días de destierro en Santiago de Chile, llenó con habitualidad columnas de El Mercurio de Valparaíso y de El Progreso de Santiago con sus críticas teatrales.

La de Sarmiento es una naumaquia rioplatense, que en un imponente escenario natural despliega naves y gladiadores para un juego de guerra que combina la grandiosidad de los espacios abiertos de Julio César con la representación más escenográfica de los anfiteatros de Nerón; y está cargado de fogonazos de cañones, y de explosiones y llamaradas de alguna santabárbara que echa sus fuegos sobre el río.

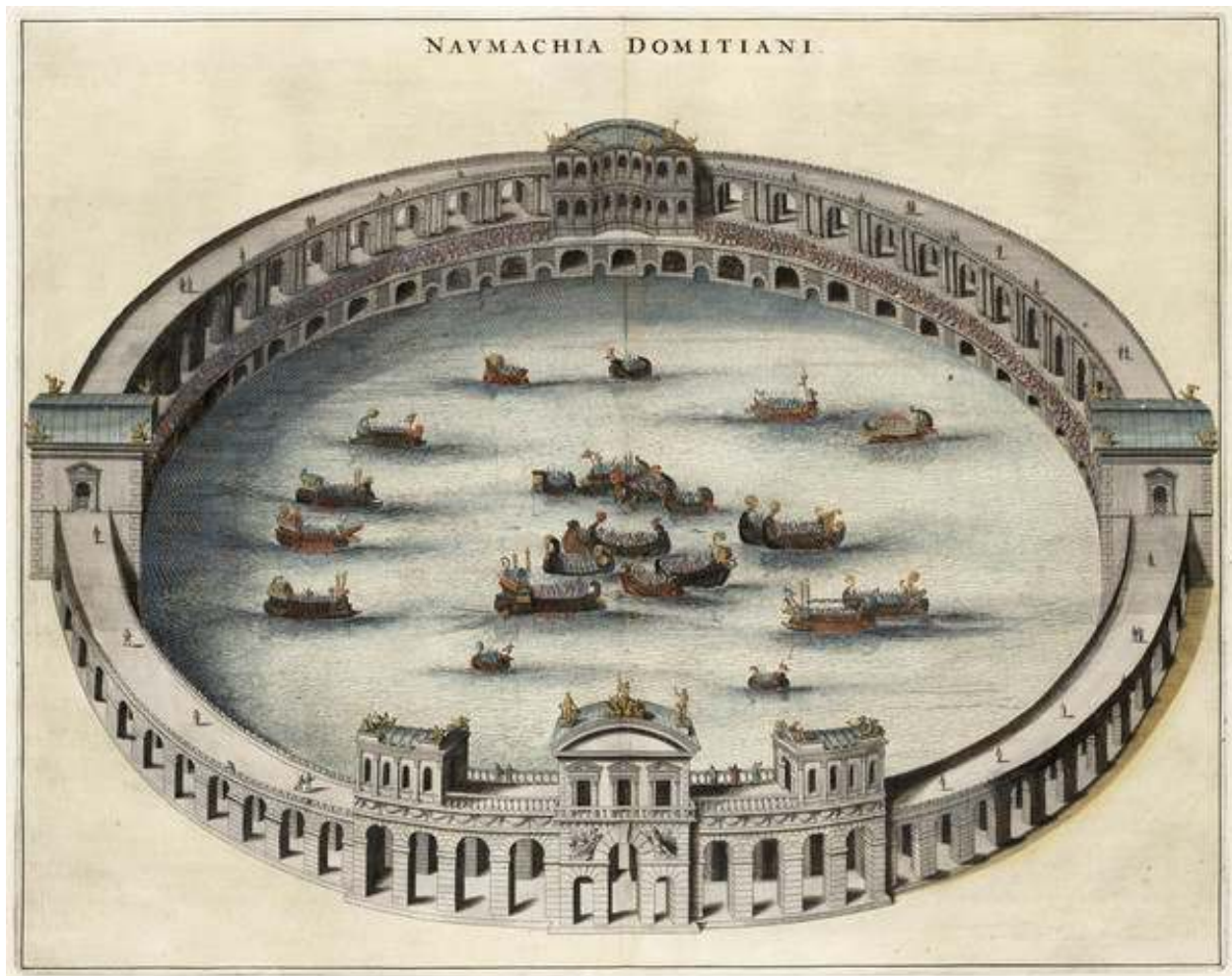

FIgURA 4: NAUMACHIA DOMITIANI, 1663

Naumaquia, entonces, donde lo más destacable son el artificio y la representación como espectáculo. $\mathrm{O}$ la verosimilitud y la pulsión narrativa, sin apego a la historia como verdad, como en la Batalla naval en el golfo de Nápoles de Pieter Brueghel el viejo, que representa un combate naval que no necesariamente ha ocurrido, y que Svetlana Alpers destaca entre las vistas topográficas de puertos: 


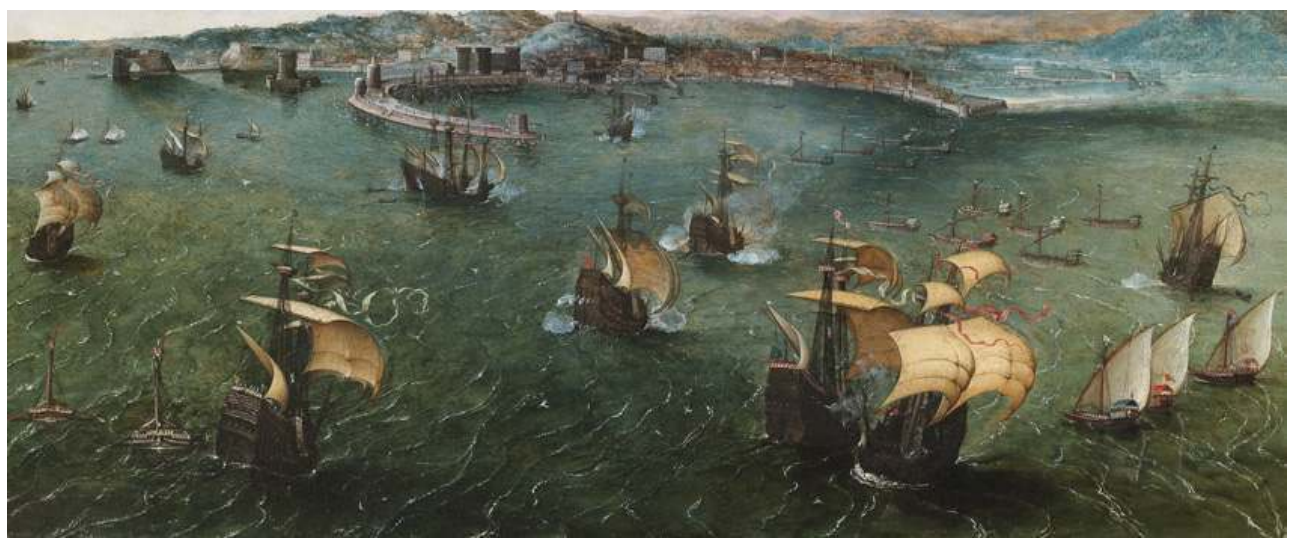

Figura 5: Batalla naval en el golfo de Nápoles ${ }^{10}$

Una vista topográfica en la que se registran batallas, como el texto de Sarmiento. Así, la bahía de Montevideo -en la que los barcos están más al abrigo de los vientos- ofrece entonces un combate naval digno de ser visto, y la rada se manifiesta como un concepto no solo náutico o militar sino también pictórico, igual que el horizonte. Las gradas del anfiteatro desde donde se asiste al espectáculo son esos miradores de techos planos, orientalistas, "que dominan hasta muy lejos la superficie de las aguas" y desde los que, en apretado montón de cabezas, los moradores de una u otra orilla del Plata escancian las vistas en los entrecortados períodos de sus conversaciones. Pero sobre todo los de Montevideo, en cuya historia cultural las azoteas y miradores constituyen un punto de articulación significativo entre la vida privada y la pública, en una trama que enlaza arquitectura, urbanismo, sociabilidad y política.

Y si, como sostiene Michel Foucault, el horizonte es una "noción pictórica, pero también estratégica"11 , no debería sorprendernos que, para poder visualizarlo, una de las primeras decisiones de la organización de la defensa de Montevideo fuera eliminar algunos obstáculos que se interponían en la línea de fuego ${ }^{12}$. Sarmiento que -no lo olvidemostambién es militar es sobre todo experto en horizontes poéticamente explotados y puede elevarlos o bajarlos como los pintores holandeses del siglo XVII. Cuando los baja, el cielo replica -como en una fata morgana- los chisporroteos que ha esparcido antes en la superficie de las aguas: 
al a larde del cuadrajesimo octavo dia de mar, el sol empezabu a ponerse, como he dicho, entre nubarrones torbos; i no bien se habia ocultado tras el ancho lomo de las aguas, por todos los estremos del horizonte asomaban lentamente densas masas de nubes prenadas de tempestades. Oh! la tempestad eléctrica, para quien ha habitado largos años las calladas costas chilenas, tiene encantos májicos cuando el estampido del trueno ha sacudido nuestros oidos desde la cuna. Habia iluminacion en los cielos aquella noche; los refusilos del horizonte ocupaban los entreactos del rayo que surcaba el espacio : nuestra frajil barca tenia empavezados de fuegos de santelmo sus mástiles, i la sucesion de luz solar, i de noche oscura encandilaba los ojos fijos en algun punto de las nubes, anhelando sorprender la sábita iluminacion fuljente. Mui tarde aun de la noche permaneciamos unos cuantos en las banquetas de proa, gozando del espectáculo, conmovidos nuestros nervios acaso por la superabundancia de electricidad

Facsímil $6^{13}$

19 Regisseur y pintor, Sarmiento compone. Primero, el lienzo que decora el escenario, en el atardecer: el sol penetra las nubes y va cayendo, sinestésica y kinestésicamente, sobre las aguas que tienen lomo, como los potros de la pampa. La marcación de la línea del horizonte le permite ubicar los elementos en el plano. El celaje está compuesto por nubes cargadas y torvas: tienen la fiereza de la mirada de Quiroga (meten miedo). Telón de fondo e iluminación de base despiertan el apóstrofe al que Sarmiento es tan afecto: "Oh! la tempestad eléctrica", y de ese modo recupera para la atmósfera lo que solemos atribuirle casi exclusivamente al mar: su "perturbación violenta", que no otra cosa es la tempestad; y, para sí mismo, gana el sonido "mágico" del estampido del trueno de las noches de su San Juan natal que el cielo del destierro santiaguino le ha venido retaceando. La parrilla de la iluminación se activa a fuerza de golpes de luz, que dispara sus relámpagos o refucilos para escandir "los entreactos del rayo", confirmando una sospecha: Sarmiento está moviendo los hilos de la tramoya de un teatro natural.

20 La iluminación del cielo ahora nocturno se derrama sobre la Enriqueta (la nave en la que se embarcó en Valparaíso cuarenta y ocho días antes de esta escena) para regalarle también los chisporroteos celestes de los fuegos de Santelmo al dar sobre sus mástiles. Alborozo o temor de los navegantes, los corposantos en la rada de esta Montevideo sitiada ofrecen un espectáculo en abismo: Sarmiento se hace ver mirando el cielo que estalla en luces y colores. ¿Acaso habrá leído el canto V de Os lusíadas?: 


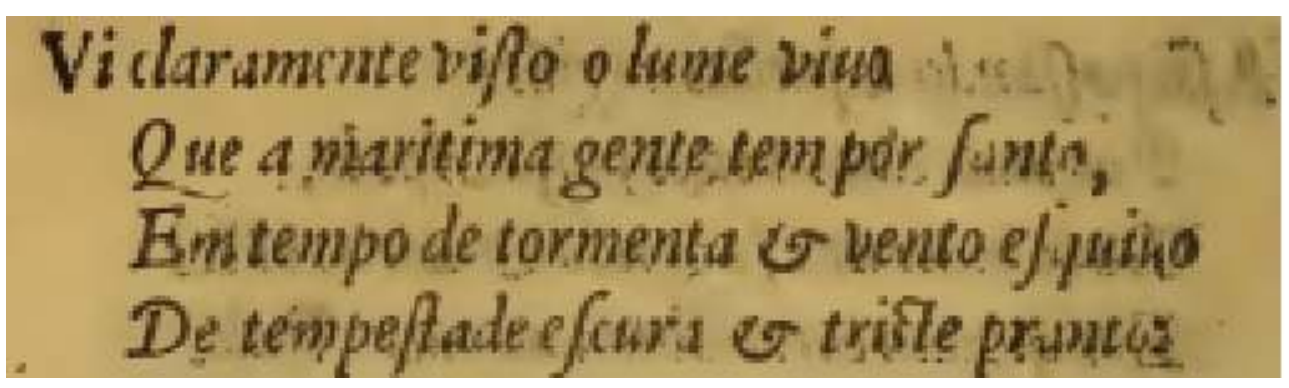

Facsímil $7^{14}$

21 Como Camões como Darwin como Melville, Sarmiento se extasía frente a las descargas eléctricas de las nubes sobre los palos de los barcos que su admirado Benjamin Franklin supo explicar entre la ciencia y la lírica. Hay "superabundancia de electricidad", acota un Sarmiento hiperkinético que en Copiapó, diez años antes, había sufrido un ataque cerebral que lo tuvo debatiéndose entre la vida y la muerte y que tal vez, como la septicemia de Borges, haya producido en él una iluminación que marcaría a fuego su proyecto estético, porque regresa a San Juan y empieza a encadenar sus ideas a las acciones públicas ${ }^{15}$. Quizá sea el mismo fluido que en la tormenta en la pampa que diseña en el capítulo II de Facundo se abate sobre el gaucho que la cruza para sumirlo -como al Saint Preux de La nueva Eloísa de Rousseau en el abismo vertical de los Alpes- en el perplejo vaivén entre la realidad y la fantasía, entre el respeto y el temor, entre la magnificencia y lo aterrador de la naturaleza, entre la masa de tinieblas y la luz imponente de los rayos que le dejan su marca y para cuyo despliegue visual Sarmiento baja considerablemente la línea del horizonte, de modo que el esplendor de sus destellos pueda cruzar la superficie casi completa de la tela, maestro de la ekphrasis como es. Son las luces y sombras que quedan "hondamente grabadas" en la imaginación, como sucede cuando, cerrados ya los ojos, el disco del sol que se ha estado observando queda fijado en la retina.

El afterimage -la persistencia retiniana- es la imagen que ofrece como un don, un efecto óptico pero también moral para Sarmiento, que sabe que el gaucho de la pampa vive inmerso en el desconcierto que le marca la tierra en la que habita, con la muerte al acecho, haciéndolo propenso al juego de la imaginación, que es casi un desvarío poético ${ }^{16}$. Sarmiento traza un cuadro verdaderamente sublime -de luz, soledad y sonido- con su tormenta en la pampa, para convertirla en un silogismo que también es político:

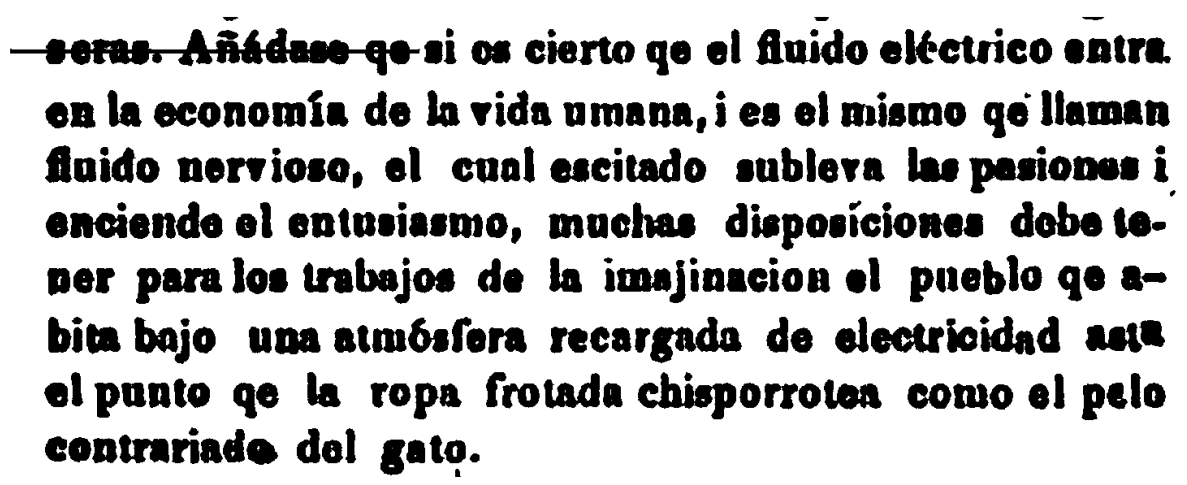

Facsímil $8^{17}$ 
Corren así fluidos eléctricos que Sarmiento, que sabe de escenografías, espectáculos teatrales y aparatos ópticos, enciende, suaviza o apaga para convertir su literatura en un campo de operaciones visuales. Ars magna lucis et umbrae, podríamos decir que es su obra, parafraseando el libro de Athanasius Kircher (de 1645-1646), donde se explica el ¿imaginario? incendio que el ingeniero y matemático Arquímedes, que ideó la defensa de Siracusa -sitiada por los romanos entre 214 y 212 a. C.-, provocó empleando espejos ustorios para hacer arder, a la distancia y por convergencia de los rayos del sol, los barcos de la flota de Marcelo.

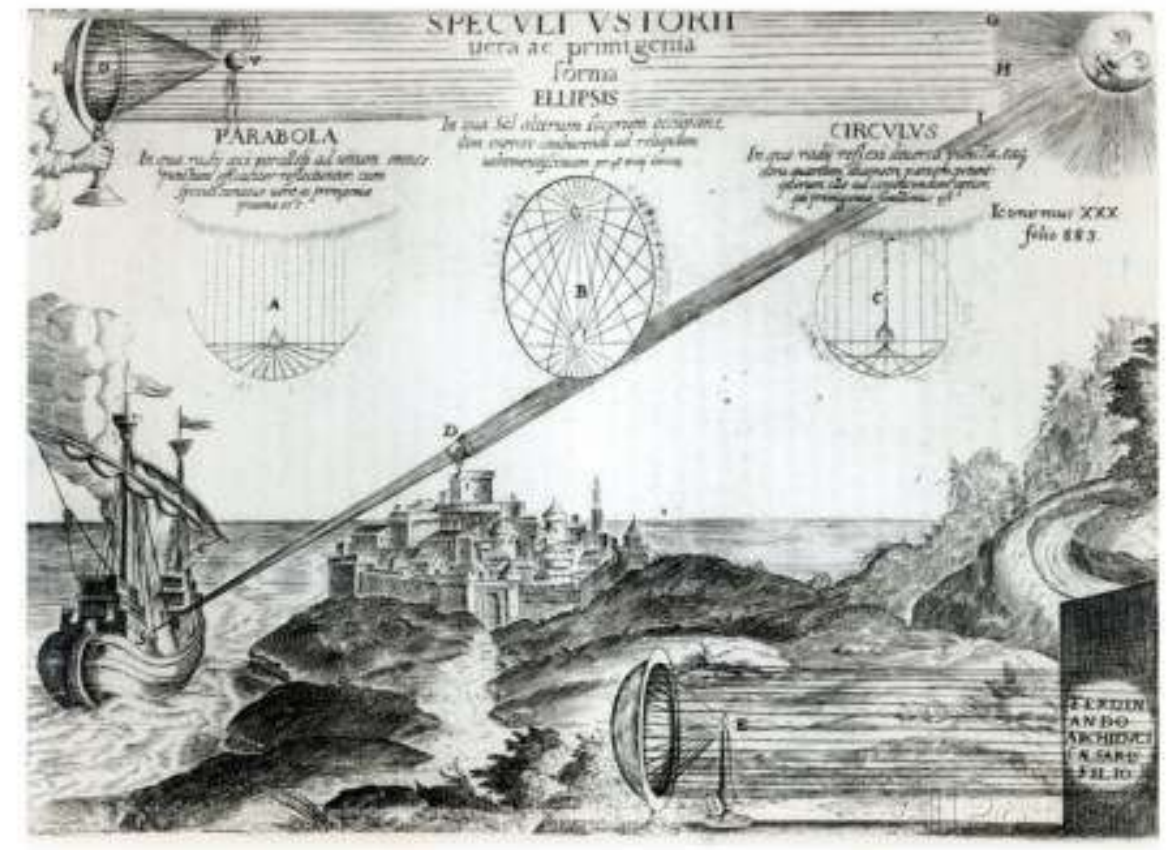

Figura 6: Espejos ustorios de Arquímedes en el Sitio de Siracusa ${ }^{18}$

Recordemos, si no, el fragmento en que Sarmiento hizo foco en una explosión: 
periatedomina Una tarde, como en las escenas de toros en España, el combate se prolongaba, i a la luz del sol que se escondia tras los pajonales de la Pampa, se sucedian los fogonazos de los cañones que iluminaban por momentos los mástiles i cascos indefinibles de los buques proximos a abordarse. De repente una inmensa llamarada alumbra el espacio; un volcan lanza al cielo una columna de llamas bastante a iluminar de rojo las pálidas caras de aquella muchedumbre de pueblo ávido de emociones i de combates, i al fragor del cañoneo se sucede el silencio sepulcral del espanto de los combatientes mismos. Un buque habia volado, ineendiada la San-

Facsímil 919

El sol, cayendo sobre los pajonales de la pampa; los fogonazos de los cañones, que dejan ver los barcos; y en las balizas de Buenos aires, Sarmiento tramoyista, colorista e iluminador (iluminador: como se dice del que compone el juego de luces en un teatro, pero también del que ilustra y pinta a mano las letras de caligrafía esmerada en un manuscrito) dispone sus espejos ustorios para hacer entrar en llamas su volcán náutico, como un Arquímedes doméstico que, en esa memoria guerrera del Río de la Plata que recupera cuando está a punto de entrar en la Montevideo sitiada, sabe encender sus propios fuegos y quemar naves sobre los ríos para ilusión de todas las historias.

\section{NOTAS}

1. Domingo F. Sarmiento, Viajes en Europa, África i América, Santiago, Imprenta de Julio Belin i C.a , 1849 , p. 36. Siguiendo la voluntad de la autora del artículo, se reproduce el texto de manera facsimilar (N. de los E.).

2. Álbum de la Plata, Colección de las vistas y costumbres remarcables de esta parte de la América del Sur, dibujadas por D. Adolphe D'Hastrel, litografiadas por Ciceri, Sabatier, Hubert-Clercet, C. Muller y Ad. D'Hastrel, París, Casa de los Sres. Cihaut Frère, s/f.

3. Ibidem. Litografía, 1842.

4. Estamos frente a uno de los dos modelos establecidos por la pintura nórdica, como recuerda Marta Penhos, donde se representa "el sitio, sea la ciudad, establecimiento o población indígena, desde el río o el mar, con embarcaciones en los primeros planos y los perfiles o accidentes 
geográficos y/o edificios en los planos posteriores. [...] Son visiones de las costas desde el mar, con un espacio poco profundo que se despliega en una línea" (Ver, conocer, dominar. Imágenes de Sudamérica a fines del siglo XVIII, Buenos Aires, Siglo XXI, 2005, p. 326).

5. Sarmiento, Viajes, op. cit., p. 36-37.

6. Giuliana Bruno, Atlas of emotion. Journeys in Art, Architecture, and Film, New York,Verso, 2002, p. 177.

7. Cf. Domingo F. Sarmiento, "Los temblores de Chile y la arquitectura" (Sud-América, 9 de abril de 1851), en Obras de Domingo F. Sarmiento, tomo II: “Artículos críticos y literarios. 1842-1853", Santiago de Chile, Imprenta Gutenberg, 1887; Raúl Antelo "Arte y arché. El luto de la historia" y Fernando Aliata, "Contemplar y recordar. Sarmiento frente a la arquitectura, el paisaje y la ciudad", en Adriana Amante (dir.), Sarmiento, vol. IV de Noé Jitrik (dir.), Historia crítica de la literatura argentina, Buenos Aires, Emecé, 2012. Y, para una lectura del orientalismo desde la arquitectura, Jorge Francisco Liernur, "Orientalismo y arquitectura moderna; el debate sobre el techo plano", en Block. Revista de cultura de la arquitectura, la ciudad y el territorio, número 8, Buenos Aires, Universidad Torcuato Di Tella, marzo de 2011. En este contexto, la dicotomía civilizaciónbarbarie se juega en la alternativa entre materiales para la construcción: la solidez de los ladrillos o la precariedad de los adobes.

8. Sarmiento, Viajes, op. cit., p. 37.

9. Sarmiento, Viajes, op. cit., p. 31-32.

10. Pieter Brueghel el viejo, óleo sobre tabla, c. 1556.

11. "Preguntas a Michel Foucault sobre la geografía", en Microfísica del poder, Madrid, Ediciones de la Piqueta, 1979, p. 116.

12. Fernando Aliata y Graciela Silvestri -en un libro pionero y decisivo para el desarrollo de los estudios sobre la geografía cultural y la cultura visual y paisajística en la Argentina- ofrecen una síntesis certera del origen del término landscape pensado como "actividad proyectual sobre el territorio" que, antes que al arte del paisaje, se remonta al desarrollo científico y técnico de la ciencia militar durante los siglos XVII y XVIII (El paisaje en el arte y las ciencias humanas, Buenos Aires, Centro Editor de América Latina, 1994, p. 125-126).

13. Sarmiento, Viajes, op. cit., p. 36-37.

14. Luis de Camões, Os lusiadas, Lisboa, Antonio Gõçalves Impressor, 1572, Canto V, p. 82 bis, fragmento de la estrofa 18 del canto V. El origen de la denominación del fenómeno alterna entre asociar los fuegos al nombre de San Pedro Telmo Gonçalves o Pedro Telmo, patrono de los navegantes, que supo detener el furor de una tormenta eléctrica para que la palabra de dios pudiera ser oída y la posibilidad de que sea la pronunciación deformada de Sant Erasmo, también protector de los marineros. San Pedro Telmo pertenecía a la cofradía de "Corpo santo": de ahí la sinonimia. Cf. Luís Miguel Bernardo, Histórias da luz e das cores, vol. 1, Porto, Editora Universidade de Porto, 2009, p. 254-257.

15. En Recuerdos de provincia, vincula el episodio médico al comienzo de su actuación pública (en Obras completas de Domingo F. Sarmiento, tomo III. Defensa, Recuerdos de provincia, Necrolojías y biografías, Santiago de Chile, Imprenta Gutenberg, 1885, p. 174-175). Nerio Rojas sospecha que pudo haber sido una fiebre tifoidea la causante del ataque, cuadro que pudo ocasionarle "accesos de manía aguda, delirio de varias formas, alucinaciones, vociferaciones" (Psicología de Sarmiento, Buenos Aires, Guillermo Kraft, 1961, p. 30).

16. Vengo trabajando estas imágenes subyugantes de Sarmiento desde hace un tiempo. Cf. Adriana Amante, "Sarmiento el boletinero: del diario de campaña al libro de vistas y paisajes", en Adriana Amante, Sarmiento, op. cit.; "El poder de un libro o el Facundo como afterimage", en Mauricio Meglioli y Ricardo de Titto (coord.), Una y otra vez, Sarmiento, Buenos Aires, Prometeo, 2016; y "Prólogo" a Domingo F. Sarmiento, Diez fragmentos comentados, Buenos Aires, EUFyL, 2016.

17. Domingo F. Sarmiento, Civilización i barbarie. Vida de Juan Facundo Quiroga i aspecto físico, costumbres, i abitos de la República Arjentina, Santiago, Imprenta del Progreso, 1845, p. 44. 
18. Athanasius Kircher, Ars magna lucis et umbrae (1645-1646).

19. Sarmiento, Viajes, op. cit., p. 32-33.

\section{RESÚMENES}

Luego de la publicación del Facundo y en una escala de su viaje por Europa, África y América, a mediados de diciembre de 1845, Domingo F. Sarmiento arriba a Montevideo, que desde 1843 y hasta 1851 estaría sitiada por Manuel Oribe. En una urdimbre de discurso político, analogías didácticas y manifestaciones programáticas, Sarmiento despliega un arsenal estético e ideológico para delinear imágenes de la ciudad asediada gracias a su diestro manejo de la écfrasis, que hace de la materia verbal un instrumento de la cultura visual, dispendiosa -en su caso- en vistas urbanas, composiciones arquitectónicas y gestos orientalistas, y hábil para la conjugación de luces y sombras en el diseño de tormentas, naumaquias e incendios, que lo imponen como el regisseur de la memoria guerrera del Río de la Plata.

A la mi-décembre 1845, à la suite de la publication du Facundo et d'une escale lors de son voyage en Europe, Afrique et Amérique, Domingo F. Sarmiento arrive à Montevideo. Entre 1843 et 1851 la capitale de l'Uruguay se trouve sous le siège de Manuel Oribe. Grâce à un mélange de discours politique, analogies didactiques et manifestations programmatiques, Sarmiento articule un ensemble esthétique et idéologique. Cet ensemble veut dessiner les images de la ville siégée à travers la maitrise de l'ekphrasis en faisant de la matière verbale un instrument de la culture visuelle. Sarmiento arrive à le faire grâce aux nombreuses perspectives urbaines, les compositions architecturelles, les gestes orientalistes ainsi qu'à travers le mélange de lumières et d'ombres dans la conception d'orages, naumachies et incendies. Sarmiento s'impose, donc, comme le régisseur de la mémoire guerrière du Río de la Plata.

Domingo F. Sarmiento arrives in Montevideo in December 1845 after the publication of Facundo and a stopover on his trip to Europe, Africa and America. Between 1843 and 1851, the capital of Uruguay is under the siege of Manuel Oribe. Sarmiento builds an aesthetic and ideological ensemble through a mixture of political discourse, didactic analogies and programmatic manifestations. He wants to draw the images of the Montevideo's siege through the mastery of ekphrasis by making the verbal material an instrument of visual culture. Sarmiento does this with many urban perspectives, architectural compositions, orientalist gestures, and the mixture of lights and shadows in the design of storms, naumachies and fires. Sarmiento becomes the steward of the war memory of Río de la Plata.

\section{ÍNDICE}

Mots-clés: Sarmiento, Le grand siège de Montevideo, perspectives urbaines et topographiques, orage, naumachie.

Keywords: Sarmiento, urban and topographical views, The great Montevideo's siege, strom, sea battle

Palabras claves: Sarmiento, Sitio Grande de Montevideo, vistas urbanas y topográficas, tormenta, naumaquia. 
AUTOR

ADRIANA AMANTE

Universidad de Buenos Aires

amante@retina.ar 